\title{
The effect of mandibular advancement on upper airway structure in obstructive sleep apnoea
}

\author{
Andrew S L Chan, ${ }^{1,2,3}$ Kate Sutherland, ${ }^{1,2}$ Richard J Schwab, ${ }^{4}$ Biao Zeng, ${ }^{1,2,3}$ \\ Peter Petocz, ${ }^{5}$ Richard W W Lee, ${ }^{1,2,3}$ M Ali Darendeliler, ${ }^{6}$ Peter A Cistullii, ${ }^{1,2,3}$
}

- Supplementary tables are published online only. To view these files please visit the journal online (http://thorax.bmj. com).

${ }^{1}$ Centre for Sleep Health and Research, Department of Respiratory Medicine, Royal North Shore Hospital, St Leonards, NSW, Australia

${ }^{2}$ Woolcock Institute of Medical Research, University of Sydney, NSW, Australia

${ }^{3}$ Department of Respiratory and Sleep Medicine, St George Hospital, University of New South Wales, NSW, Australia ${ }^{4}$ University of Pennsylvania, Philaldephia, Pennsylvania, USA ${ }^{5}$ Department of Statistics, Macquarie University, NSW, Australia

${ }^{6}$ Department of Orthodontics, Faculty of Dentistry, Sydney Dental Hospital, University of Sydney, NSW, Australia

\section{Correspondence to}

Professor Peter Cistulli, Centre for Sleep Health and Research, Department of Respiratory Medicine, Royal North Shore Hospital, St Leonards, NSW 2065, Australia; cistullip@med.usyd.edu.au

Received 19 November 2009 Accepted 25 May 2010

\section{ABSTRACT}

Background The mechanisms by which mandibular advancement splints (MAS) improve obstructive sleep apnoea (OSA) are not well understood. This study aimed to evaluate the mechanism of action of MAS by assessing their effect on upper airway structure in patients with OSA.

Methods Patients were recruited from a sleep disorders clinic for treatment with a custom-made MAS. MRI of the upper airway was performed during wakefulness in the supine position, with and without the MAS.

Results Sixty-nine patients with OSA were recruited. Treatment with the MAS reduced the apnoea-hypopnoea index (AHI) from 27.0 14.7 events/h to $12.2 \pm 12.5$ events/h $(p<0.001)$. There was an increase in the total airway volume with mandibular advancement $\left(16.5 \pm 0.7 \mathrm{~cm}^{3}\right.$ vs $18.1 \pm 0.8 \mathrm{~cm}^{3}$; $\mathrm{p}<0.01$ ) that occurred predominantly because of an increase in the volume of the velopharynx $\left(5.7 \pm 0.3 \mathrm{~cm}^{3}\right.$ vs $\left.6.5 \pm 0.3 \mathrm{~cm}^{3} ; p<0.001\right)$. This increase in airway calibre was associated with an increase in the lower anterior facial height $(6.8 \pm 0.1 \mathrm{~cm}$ vs $7.5 \pm 0.1 \mathrm{~cm}$; $p<0.001$ ), reduction in the distance between the hyoid and posterior nasal spine $(7.4 \pm 0.1 \mathrm{~cm}$ vs $7.2 \pm 0.1 \mathrm{~cm}$; $p<0.001$ ), lateral displacement of the parapharyngeal fat pads away from the airway (right parapharyngeal fat pad $0.17 \pm 0.02 \mathrm{~cm}$; left parapharyngeal fat pad $0.22 \pm 0.02 \mathrm{~cm}$ ) and anterior movement of the tongue base muscles $(0.33 \pm 0.03 \mathrm{~cm})$. Subanalyses in responders and non-responders to MAS treatment showed that the increase in upper airway calibre with mandibular advancement occurred only in responders. Conclusion These results suggest that the mechanism of action of MAS is to increase the volume of the upper airway, predominantly by increasing the volume of the velopharynx, and this increased volume is associated with changes in the surrounding bony and soft tissue structures.

\section{INTRODUCTION}

Mandibular advancement splints (MAS) are increasingly being used in the treatment of obstructive sleep apnoea (OSA) as an effective alternative to continuous positive airway pressure (CPAP). ${ }^{1-5}$ While CPAP remains the 'gold standard' because it is a highly efficacious treatment, there is a need for other treatment options because the clinical effectiveness of CPAP is often limited by poor patient acceptance and tolerance, and suboptimal compliance. ${ }^{6-8}$

MAS protrude the mandible with the aim of increasing upper airway calibre and thereby preventing collapse of the upper airway during sleep. ${ }^{4}$ However, the mechanisms by which MAS improve OSA are not well understood. Limited studies have identified an effect of mandibular advancement on aspects of the structure and function of the upper airway. ${ }^{9-16}$ Importantly, these predominantly used cephalometric x-rays which are limited by their two-dimensional nature. However, soft tissue volumes and movements, and the interaction between upper airway structural parameters and treatment response have never been systematically studied in patients using an oral appliance. A better understanding of the biomechanical mechanisms that mediate the efficacy of MAS may have important clinical implications, including the development of more efficacious appliances, and may improve the selection of patients for this treatment modality.

MRI is a powerful, non-invasive research tool and is probably one of the best methods for assessing the three-dimensional structure of the upper airway lumen and the surrounding soft tissue structures. ${ }^{17}$ Therefore, this study aimed to evaluate the mechanism of action of MAS in patients with OSA by assessing their effect on upper airway structure during wakefulness using MRI. Preliminary results of this study have been previously reported in the form of abstracts. ${ }^{18} 19$

\section{METHODS \\ Subjects}

Patients were prospectively recruited from a sleep disorders clinic in a university teaching hospital for treatment of OSA with a custom-made MAS. Inclusion criteria included the presence of at least two symptoms of OSA (such as snoring, witnessed apnoeas, fragmented sleep or daytime sleepiness) and evidence of OSA on nocturnal polysomnography (apnoea-hypopnoea index (AHI) of at least 10 events/h). Patients were excluded if there were contraindications to MAS treatment (such as periodontal disease, insufficient number of teeth or an exaggerated gag reflex). Patients with ferromagnetic prostheses, a contraindication to MRI, were also excluded. The study was approved by the institutional ethics committee and written informed consent was obtained from all patients.

\section{MAS Treatment}

A custom-made two-piece MAS was used (SomnoDent MAS; SomnoMed, Crows Nest, Australia), the design features and efficacy of which have previously been published. ${ }^{20-25}$ To permit MRI of the upper airway with the MAS, the 
appliance did not incorporate the usual adjustable screw mechanism. This modified device is shown in figure 1. Acclimatisation occurred over a period of 6-8 weeks. During this time, the degree of mandibular advancement was incrementally titrated until the maximum comfortable limit was achieved. For this study, this was achieved by modification of the acrylic coupling mechanism. Since this method of titration was not as convenient as the adjustable screw mechanism, larger increments were used over the standard 6-8 week acclimatisation period, but in all other respects the protocol was identical to that of previously published studies. ${ }^{20-25}$

\section{Polysomnography}

Polysomnography, as previously described, ${ }^{20}$ was performed to determine treatment outcome at the completion of the acclimatisation period, and was scored according to standard criteria. $^{2627}$ Apnoeas were defined by a cessation of airflow for at least $10 \mathrm{~s}$ in association with oxygen desaturation of at least $3 \%$ or an arousal. Hypopnoeas were defined by a reduction in the amplitude of airflow, as measured using nasal pressure or thoracoabdominal wall movement, by $>50 \%$ of the baseline measurement for $>10 \mathrm{~s}$, in association with oxygen desaturation of at least $3 \%$ or an arousal.

\section{Treatment outcome}

An objective assessment of treatment outcome was made based on the polysomnographic response. In previous efficacy studies, we used a rigorous definition of treatment outcome, with a complete response defined by a reduction of AHI to $<5$ events/h and a partial response defined by $a \geq 50 \%$ reduction in $\mathrm{AHI}$. However, for this mechanistic study, we chose to include those who obtained a partial response as a 'responder' because the biomechanical changes that mediate a complete response are likely to be similar to the changes which mediate a partial response. It also reflects clinical practice, with patients often obtaining clinical benefit despite incomplete resolution of OSA. Specifically, 'responders' were defined by a $\geq 50 \%$ reduction in AHI. 'Non-responders' were defined by a $<50 \%$ reduction in AHI.

\section{MRI of the upper airway}

Spin-echo MRI of the upper airway was performed during wakefulness, with and without the MAS, in random order, using a Philips INTERA 1.5 T MRI scanner (Philips Electronics, The

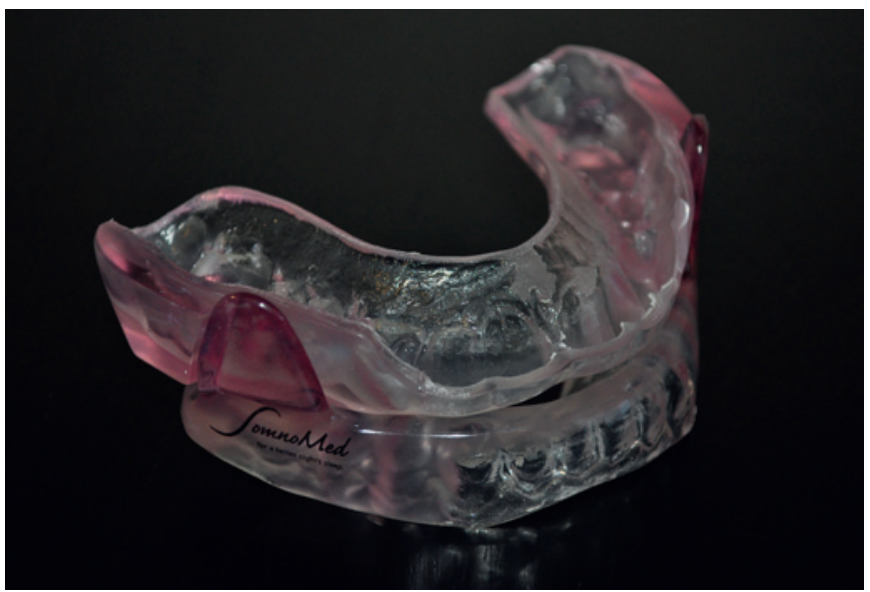

Figure 1 The custom-made two-piece mandibular advancement splint (MAS) used in the study (a modification of the SomnoDent MAS). To permit MRI of the upper airway with the MAS, the appliance did not incorporate the usual adjustable screw mechanism.
Netherlands) at the completion of the acclimatisation period With the aid of a gantry beam, the patient's head was positioned with the Frankfort plane perpendicular to horizontal. Foam pads were used to secure the head in this position. MRIs were acquired with a receive-only neck coil. Throughout the scan, patients were asked to breathe normally through their nose and to refrain from swallowing. Patients were also instructed to keep their mouth closed and to maintain a relaxed bite, with the tongue touching the front teeth.

An initial sagittal scan was performed to confirm head position. Contiguous T1-weighted spin-echo images were acquired through the long axis of the airway, centred on the mid-sagittal plane (50 slices, $1.25 \mathrm{~mm}$ thickness, $272 \times 512$ matrix, field of view (FOV) $240 \mathrm{~mm}$ ). Axial scans of the upper airway (50 slices, $3 \mathrm{~mm}$ thickness, $224 \times 512$ matrix, FOV $250 \mathrm{~mm}$ ) were then acquired from above the level of the nasopharynx to below the level of the vocal cords. The acquisitions were stored in the Digital Imaging and Communications in Medicine (DICOM) format.

\section{Anatomical definitions, measurements and analyses}

Volumetric upper airway reconstructions were performed from the axial images with image analysis software (Amira 4.1; Visage Imaging, San Diego, USA) using previously described techniques. $^{28} 29$ The analysis involved examining three-dimensional volumes of the following structures: airway lumen, parapharyngeal fat pads, soft palate, tongue (genioglossus and base of tongue muscles) and lateral pharyngeal walls. The anatomical definitions, measurements and analysis strategies used have been previously validated. ${ }^{30}$ The upper airway was divided into three segments (see figure 2): velopharynx (from the hard palate to the tip of the uvula), oropharynx (from the tip of the uvula to the tip of the epiglottis) and hypopharynx (from the tip of the epiglottis to the level of the vocal cords). Airway length was defined by the sum of the thickness of the axial images for the velopharyngeal, oropharyngeal and hypopharyngeal segments. The movement of soft tissue structures (parapharyngeal fat pads, soft palate, tongue and lateral pharyngeal walls) in response to mandibular advancement was assessed using the centroids of these structures (ie, the point designated by the mean of the coordinates of all the points in the set). The following cephalometric measurements were performed: sella-nasion-A point (SNA) angle, sella-nasion-B point (SNB) angle, A point-nasion-B point (ANB) angle, basion-sella-nasion (BaSN) angle, mandibular plane angle, and distance between anterior nasal spine and gnathion (ANS-Gn, a measure of lower anterior facial height). As indicators of hyoid position, the following measurements were also performed: distance between hyoid and C3 vertebra (H-C3), distance between hyoid and posterior nasal spine (H-PNS) and distance between hyoid and gnathion ( $\mathrm{H}-\mathrm{Gn})$. The mid-sagittal image was used to derive cephalometric measurements, with the exception of the mandibular plane angle which was obtained from three-dimensional reconstructions, and we have shown good intraobserver reproducibility using this technique (mean coefficient of variation $1.8 \pm 0.7 \%$ ) when making repeated measurements on the same images. Skeletal class was determined based on the ANB angle: class I skeletal pattern (ANB angle $2-4^{\circ}$ ), class II skeletal pattern (ANB angle $>4^{\circ}$ ) and class III skeletal pattern (ANB angle $\left.<2^{\circ}\right)$. ${ }^{31}$ These cephalometric measurements are shown in figure 3.

\section{Statistical analysis}

Statistical analyses were performed using a statistical software package (SPSS 13.0 for Windows; SPSS, Chicago, Illinois, USA). Descriptive statistics for clinical characteristics of patients and MRI parameters are presented as means \pm SD and means $\pm S E M$, 
Figure 2 (A) Segments of the upper airway on mid-sagittal MRI:

velopharynx (from the hard palate to the tip of the uvula), oropharynx (from the tip of the uvula to the tip of the epiglottis) and hypopharynx (from the tip of the epiglottis to the level of the vocal cords). (B) Segmentation of upper airway structures on axial MRI: airway lumen, parapharyngeal fat pads, soft palate, tongue (genioglossus) and lateral pharyngeal walls. (a)

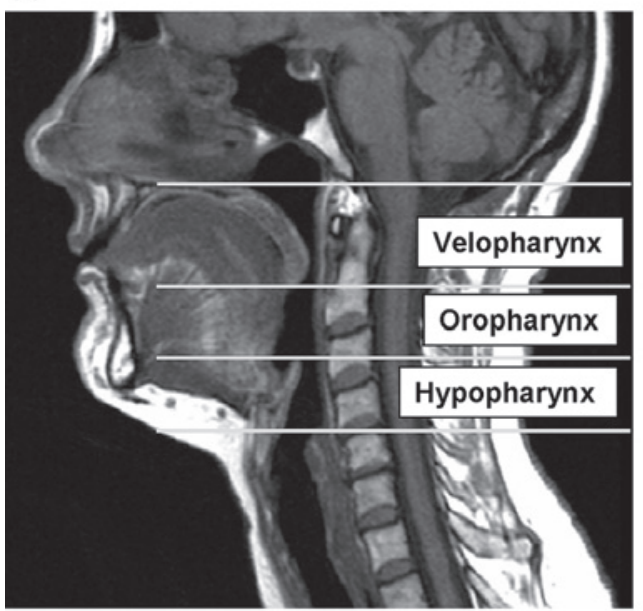

(b)

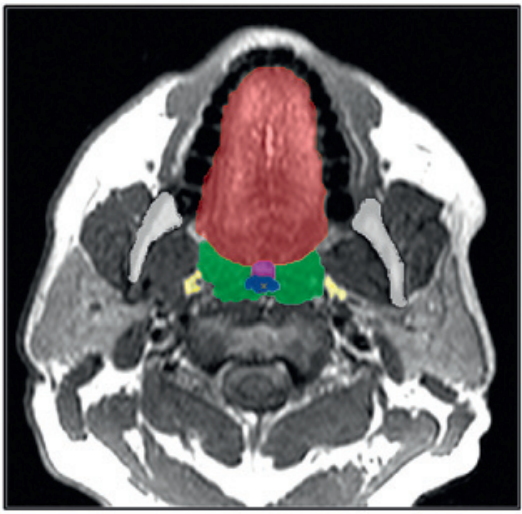

Airway

Parapharyngeal fat pads

- Soft palate Lateral pharyngeal walls

Tongue $\quad \square$ Mandible respectively. Continuous variables were normally distributed and compared using the Student t test. Categorical variables were compared using the $\chi^{2}$ test. Statistical significance was accepted if the $p$ value was $<0.01$ in order to account for multiple comparisons.

\section{RESULTS}

\section{Subjects}

Sixty-nine patients with OSA were recruited for treatment with a custom-made MAS. The clinical characteristics of these

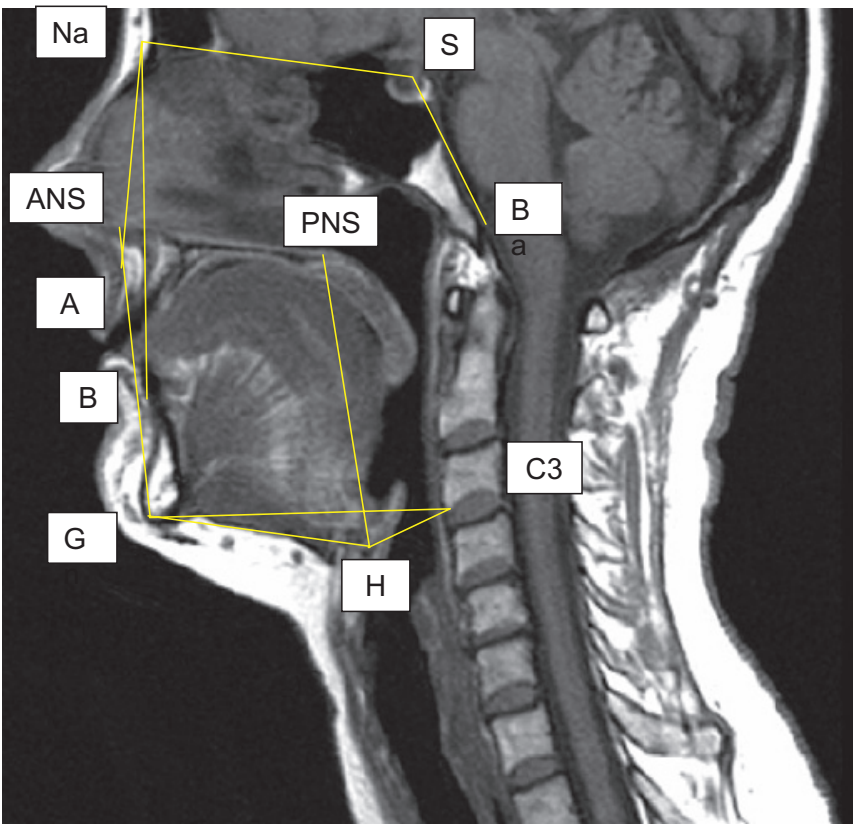

Figure 3 Cephalometric landmarks on mid-sagittal MRI: sella (S), nasion $(\mathrm{Na})$, basion $(\mathrm{B})$, anterior nasal spine (ANS), posterior nasal spine (PNS), A point (A), B point (B), gnathion $(G n)$, hyoid $(H)$ and $C 3$ vertebra (C3). Using these landmarks, the following cephalometric measurements were made: sella-nasion-A point (SNA) angle, sella-nasion-B point (SNB) angle, A point-nasion-B point (ANB) angle, basion-sellanasion (BaSN) angle, distance between anterior nasal spine and gnathion (ANS-Gn, a measure of lower anterior facial height), distance between hyoid and $\mathrm{C} 3$ vertebra $(\mathrm{H}-\mathrm{C} 3)$, distance between hyoid and posterior nasal spine (H-PNS) and distance between hyoid and gnathion $(\mathrm{H}-\mathrm{Gn})$. patients are shown in table 1 . In these patients, $17.4 \%$ had a normal skeletal class (class I occlusion), 34.8\% had a class II occlusion and $33.3 \%$ had a class III occlusion. As the focus of the study was imaging of the upper airway and did not include the nasion in all patients, there was a proportion of patients $(14.5 \%)$ in whom the skeletal class could not be determined. However, patients for whom skeletal class could not be determined did not differ with respect to age, gender, body mass index (BMI) or baseline AHI (data not shown). The mean amount of mandibular advancement was $6.5 \pm 2.3 \mathrm{~mm}$, representing $76.1 \pm 12.8 \%$ of maximum mandibular protrusion. A volumetric reconstruction of the upper airway is shown in figure 4.

\section{Treatment outcome}

Treatment with MAS reduced the AHI from 27.0 14.7 events/h to $12.2 \pm 12.5$ events/h $(p<0.001)$, with $36.2 \%$ of patients achieving a post-treatment AHI of $<5$ events/h. Of the 69 patients who participated in this study, 47 patients were responders and 22 patients were non-responders. There was no significant difference between responders and non-responders in the degree of mandibular advancement. In responders, treatment

Table 1 Clinical characteristics of patients according to treatment outcome

\begin{tabular}{llllc}
\hline & $\begin{array}{l}\text { All patients } \\
(\mathbf{n = 6 9 )}\end{array}$ & $\begin{array}{l}\text { Responders } \\
(\mathbf{n}=\mathbf{4 7})\end{array}$ & $\begin{array}{l}\text { Non- } \\
\text { responders } \\
(\mathbf{n}=\mathbf{2 2})\end{array}$ & $\begin{array}{l}\mathbf{p} \\
\text { Value* }\end{array}$ \\
\hline Male gender (\%) & $68.1 \%$ & $70.2 \%$ & $63.6 \%$ & 0.59 \\
Age (years) & $50.5 \pm 10.1$ & $49.1 \pm 10.3$ & $53.4 \pm 9.2$ & 0.095 \\
BMI (kg/m ${ }^{2}$ ) & $29.1 \pm 5.1$ & $28.3 \pm 4.6$ & $30.6 \pm 5.7$ & 0.092 \\
Skeletal class: & & & & 0.82 \\
$\quad$ Class I & $17.4 \%$ & $19.1 \%$ & $13.6 \%$ & \\
$\quad$ Class II & $34.8 \%$ & $36.2 \%$ & $31.8 \%$ & \\
$\quad$ Class III & $33.3 \%$ & $31.9 \%$ & $36.4 \%$ & \\
$\quad$ Unable to classify & $14.5 \%$ & $12.8 \%$ & $18.2 \%$ & \\
$\begin{array}{l}\text { Baseline AHI (events/h) } \\
\text { AHI with MAS (events/h) }\end{array}$ & $27.0 \pm 14.7$ & $29.7 \pm 16.3$ & $21.3 \pm 8.5$ & 0.007 \\
Complete responders & $36.2 \%$ & $53.2 \%$ & & \\
(AHI <5 events/h) (\%) & & & & \\
\hline
\end{tabular}

${ }^{*}$ Responders compared with non-responders.

AHI, apnoea-hypopnoea index; BMI, body mass index; MAS, mandibular advancement splint. 


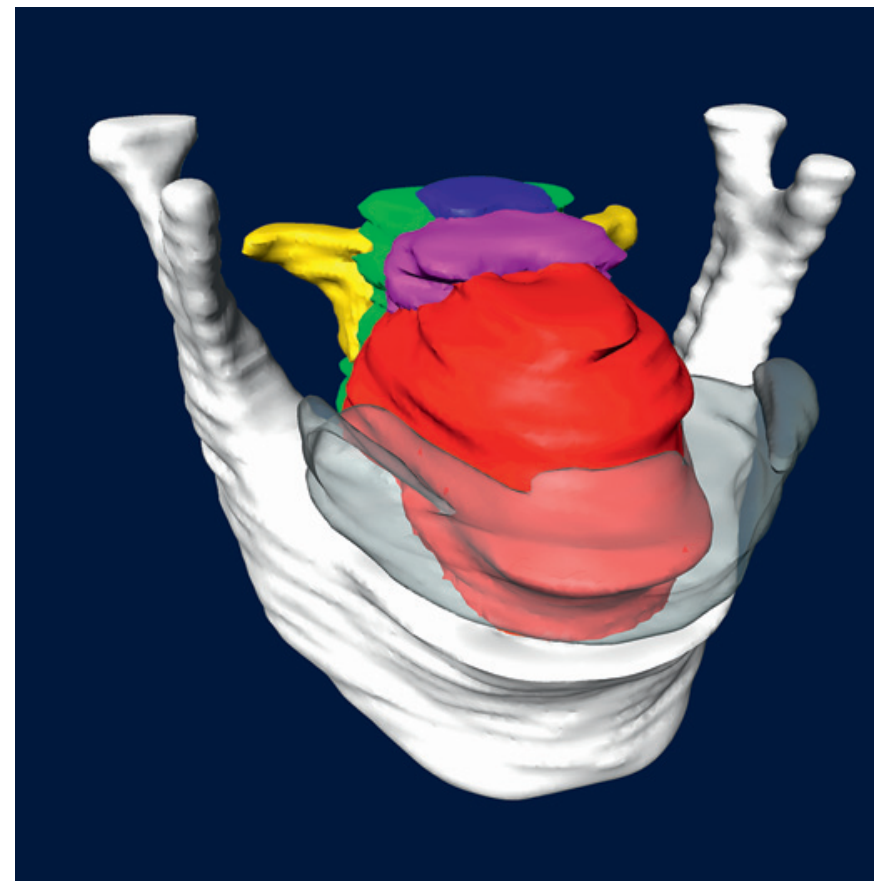

Figure 4 Volumetric reconstruction of the upper airway. The structures shown are: airway lumen (blue), soft palate (purple), tongue (red), parapharyngeal fat pads (yellow), lateral pharyngeal walls (green) and mandible (white). The MAS is shown in grey.

with MAS resulted in a reduction of AHI to a mean of $7.7 \pm 7.3$ events/h, with $53.2 \%$ of responders achieving a complete response (reduction of AHI to $<5$ events/h) and $46.8 \%$ achieving a partial response $(\geq 50 \%$ reduction in $\mathrm{AHI}$, but with residual AHI of $\geq 5$ events/h). There were no significant differences between responders and non-responders with respect to age, gender or BMI. Responders had a higher baseline AHI than nonresponders $(29.7 \pm 16.3$ events/h vs $21.3 \pm 8.5$ events/h). The clinical characteristics of responders and non-responders are shown in table 1.

\section{Effect of mandibular advancement on upper airway structure}

MRI of the upper airway demonstrated an increase in the total airway volume with mandibular advancement $\left(16.5 \pm 0.7 \mathrm{~cm}^{3}\right.$ vs $18.1 \pm 0.8 \mathrm{~cm}^{3} ; \mathrm{p}<0.01$ ). This occurred predominantly because of an increase in the volume of the velopharynx $\left(5.7 \pm 0.3 \mathrm{~cm}^{3}\right.$ vs $\left.6.5 \pm 0.3 \mathrm{~cm}^{3} ; \mathrm{p}<0.001\right)$ and was mediated by an increase in its lateral dimensions $(1.67 \pm 0.07 \mathrm{~cm}$ vs $1.91 \pm 0.07 \mathrm{~cm} ; \mathrm{p}<0.001)$, rather than antero-posterior airway dimensions. There was no change in airway length with mandibular advancement. The changes in airway volumes with mandibular advancement are shown in table 2. With respect to cephalometric parameters, mandibular advancement resulted in an increase in the lower anterior facial height $(6.8 \pm 0.1 \mathrm{~cm}$ vs $7.5 \pm 0.1 \mathrm{~cm} ; \mathrm{p}<0.001)$ and reduced the distance from the hyoid to the posterior nasal spine $(7.4 \pm 0.1 \mathrm{~cm}$ vs $7.2 \pm 0.1 \mathrm{~cm} ; \mathrm{p}<0.001)$. Mandibular advancement was also associated with lateral displacement of the parapharyngeal fat pads away from the airway (right parapharyngeal fat pad $0.17 \pm 0.02 \mathrm{~cm}$; left parapharyngeal fat pad $0.22 \pm 0.02 \mathrm{~cm})$ and anterior positioning of the base of tongue muscles $(0.33 \pm 0.03 \mathrm{~cm})$. The cephalometric changes and movement of the centroids of soft tissue structures are shown in table 3 and supplementary tables E1 and E2, and the movement of the centroids of soft tissue structures is depicted in figure 5 .
Table 2 Airway parameters without mandibular advancement splint (MAS) and with MAS (all patients; $n=69$ )

\begin{tabular}{lccc}
\hline & $\begin{array}{l}\text { Without } \\
\text { MAS }\end{array}$ & $\begin{array}{l}\text { With } \\
\text { MAS }\end{array}$ & p Value* \\
\hline Total airway volume $\left(\mathrm{cm}^{3}\right)$ & $16.5 \pm 0.7$ & $18.1 \pm 0.8$ & 0.001 \\
Minimum cross-sectional area $\left(\mathrm{cm}^{2}\right)$ & $0.49 \pm 0.04$ & $0.57 \pm 0.03$ & 0.031 \\
Airway length $(\mathrm{cm})$ & $9.4 \pm 0.1$ & $9.2 \pm 0.1$ & 0.15 \\
Velopharynx & & & \\
Volume $\left(\mathrm{cm}^{3}\right.$ ) & $5.7 \pm 0.3$ & $6.5 \pm 0.3$ & $<0.001$ \\
Antero-posterior dimensions (cm) & $1.13 \pm 0.04$ & $1.17 \pm 0.04$ & 0.22 \\
Lateral dimensions (cm) & $1.67 \pm 0.07$ & $1.91 \pm 0.07$ & $<0.001$ \\
Oropharynx & & & \\
Volume (cm ${ }^{3}$ ) & $3.7 \pm 0.2$ & $3.9 \pm 0.2$ & 0.24 \\
Antero-posterior dimensions (cm) & $1.22 \pm 0.04$ & $1.27 \pm 0.04$ & 0.13 \\
Lateral dimensions (cm) & $2.23 \pm 0.09$ & $2.34 \pm 0.08$ & 0.10 \\
Hypopharynx & & & \\
Volume (cm ${ }^{3}$ ) & $7.1 \pm 0.4$ & $7.7 \pm 0.4$ & 0.017 \\
Antero-posterior dimensions (cm) & $1.37 \pm 0.05$ & $1.47 \pm 0.05$ & 0.023 \\
Lateral dimensions (cm) & $2.50 \pm 0.08$ & $2.52 \pm 0.08$ & 0.74 \\
\hline
\end{tabular}

*Without MAS compared with with MAS.

\section{Comparison of airway structure in responders and non-responders}

At baseline, there were no significant differences between responders and non-responders with respect to the volumes of the airway and soft tissue structures, skeletal class or cephalometric measurements (see supplementary table E3). In the responders, MRI of the upper airway demonstrated an increase in total airway volume with mandibular advancement $\left(16.1 \pm 0.8 \mathrm{~cm}^{3}\right.$ vs $\left.18.1 \pm 1.0 \mathrm{~cm}^{3} ; \mathrm{p}<0.001\right)$, predominantly as a result of an increase in the lateral dimension $(1.62 \pm 0.08 \mathrm{~cm}$ vs $1.92 \pm 0.09 \mathrm{~cm} ; \mathrm{p}<0.001)$ and volume of the velopharynx $\left(5.4 \pm 0.4 \mathrm{~cm}^{3}\right.$ vs $\left.6.4 \pm 0.4 \mathrm{~cm}^{3} ; \mathrm{p}<0.001\right)$. There was an increase in the volume of the hypopharynx, but to a lesser extent $\left(7.0 \pm 0.4 \mathrm{~cm}^{3}\right.$ vs $\left.7.7 \pm 0.4 \mathrm{~cm}^{3} ; \mathrm{p}<0.01\right)$. In addition, there was an increase in the minimum cross-sectional area of the upper airway $\left(0.46 \pm 0.03 \mathrm{~cm}^{2}\right.$ vs $\left.0.56 \pm 0.04 \mathrm{~cm}^{2} ; \mathrm{p}<0.01\right)$. The effect of mandibular advancement on velopharyngeal volume was also observed within the subset of complete responders $\left(6.2 \pm 0.6 \mathrm{~cm}^{3}\right.$ vs $\left.7.2 \pm 0.7 \mathrm{~cm}^{3} ; \mathrm{p}<0.01\right)$. In contrast, there were no changes in the airway parameters in non-responders. These results are shown in table 4. Representative axial images of the upper airway from a responder and non-responder are shown in figure 6. Volumetric reconstructions of the upper airway from a responder are shown in figure 7 . Although there were subtle differences in the cephalometric changes and the movement of soft tissue structures between responders and non-responders,

Table 3 Cephalometric measurements without mandibular advancement splint (MAS) and with MAS (all patients; $n=69$ )

\begin{tabular}{lrrr}
\hline & $\begin{array}{l}\text { Without } \\
\text { MAS }\end{array}$ & \multicolumn{1}{l}{ With } \\
& MAS & p Value* \\
\hline SNA angle $\left({ }^{\circ}\right) \dagger$ & $82.5 \pm 0.7$ & $81.9 \pm 1.1$ & 0.48 \\
SNB angle $\left({ }^{\circ}\right) \dagger$ & $79.7 \pm 0.7$ & $80.1 \pm 1.4$ & 0.78 \\
ANB angle $\left({ }^{\circ}\right) \dagger$ & $2.8 \pm 0.5$ & $1.8 \pm 1.0$ & 0.26 \\
ANS-Gn distance $(\mathrm{cm})$ & $6.8 \pm 0.1$ & $7.5 \pm 0.1$ & $<0.001$ \\
$\mathrm{H}-\mathrm{C} 3$ distance $(\mathrm{cm})$ & $3.7 \pm 0.1$ & $3.8 \pm 0.1$ & 0.048 \\
$\mathrm{H}-\mathrm{PNS}$ distance $(\mathrm{cm})$ & $7.4 \pm 0.1$ & $7.2 \pm 0.1$ & $<0.001$ \\
$\mathrm{H}-$ Gn distance $(\mathrm{cm})$ & $4.7 \pm 0.1$ & $4.8 \pm 0.1$ & 0.061 \\
\hline
\end{tabular}

*Without MAS compared with with MAS.

$\dagger \mathrm{n}=57$ for SNA angle, SNB angle and ANB angle as imaging did not include the nasion in all patients.

ANB, A point-nasion-B point; ANS, anterior nasal spine; Gn, gnathion; $H$, hyoid; PNS, posterior nasal spine; SNA, sella-nasion-A point; SNB, sella-nasion-B point. 


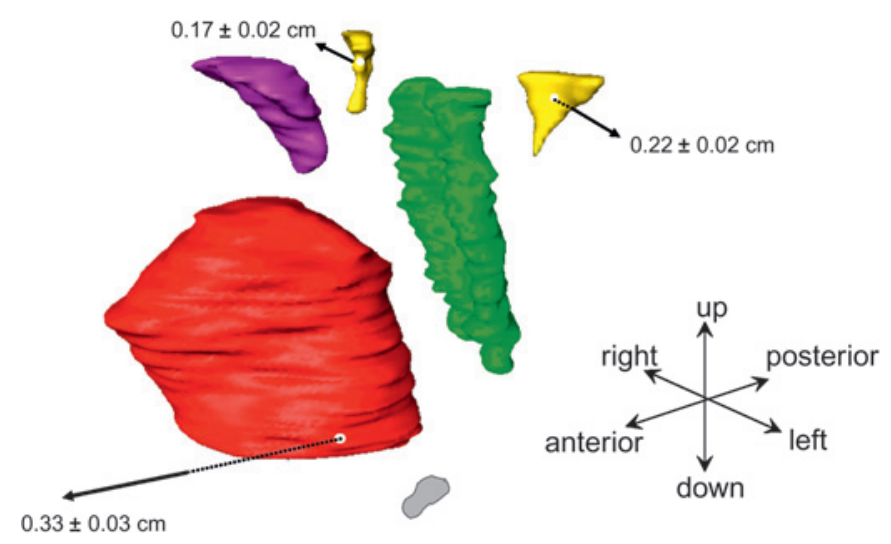

Figure 5 Movement of centroids of soft tissue structures with mandibular advancement. The structures shown are: soft palate (purple), tongue (red), parapharyngeal fat pads (yellow), lateral pharynageal walls (green) and hyoid (white). Mandibular advancement caused lateral displacement of the parapharyngeal fat pads away from the airway (right parapharyngeal fat pad $0.17 \pm 0.02 \mathrm{~cm}$; left parapharyngeal fat pad $0.22 \pm 0.02 \mathrm{~cm}$ ) and anterior positioning of the base of tongue muscles $(0.33 \pm 0.03 \mathrm{~cm})$.

these were not statistically significant (see supplementary tables E1 and E2).

\section{DISCUSSION}

Our study is the largest to use sophisticated volumetric upper airway analyses to provide a detailed evaluation of the impact of mandibular advancement on the upper airway and surrounding soft tissue structures in patients with OSA. Our study challenges the traditional thinking that the primary mechanism of action of MAS is to cause mechanical advancement of the mandible and increase the antero-posterior dimensions of the oropharynx, thereby preventing collapse of the upper airway during sleep. ${ }^{4}$ A key finding of this study is that mandibular advancement improves the calibre of the upper airway, but this occurs predominantly due to an increase in the volume of the velopharynx and is mediated by an increase in its lateral dimensions. These airway effects are associated with a number of bony and soft tissue changes, including an increase in lower anterior facial height, raised position of the hyoid, lateral displacement of the parapharyngeal fat pads away from the airway and anterior positioning of the base of tongue muscles. This work extends the findings of a previous study using nasopharyngoscopy which demonstrated that mandibular advancement improves the calibre of the velopharyngeal segment of the upper airway. ${ }^{14}$ While the precise reason for this effect on velopharyngeal patency is not resolved by our study, it is likely that soft tissue connections between the mandible, tongue, lateral pharyngeal walls and soft palate within the palatoglossal and palatopharyngeal arches are stretched by mandibular advancement, ${ }^{32}$ resulting in lateral enlargement of the velopharynx. Both the previous study using nasopharyngoscopy ${ }^{14}$ and this study also found changes of smaller magnitude in the oropharyngeal and hypopharyngeal segments of the upper airway; however, their relative contribution to the therapeutic effect of MAS is unclear. These findings are analogous to studies using MRI to assess the mechanism of action of other therapeutic interventions, such as CPAP. ${ }^{33} 34$ Upper airway dilation as a result of the application of CPAP occurred particularly in the lateral dimension, with progressive increases in CPAP resulting in increasing airway volume and thinning of the lateral pharyngeal walls. ${ }^{34}$

Another important and novel finding of our study is that there were no significant differences between responders and non-responders with respect to the volumes of the airway and soft tissue structures at baseline. Similarly there were no significant differences in cephalometric measurements at baseline. The clinical implication of this finding is that it is not possible to predict treatment response based on these anatomical characteristics, a consideration which is relevant to the selection of patients for MAS treatment. Interestingly, subanalyses in responders and non-responders showed that the increase in total airway volume with mandibular advancement was observed only in responders. This finding could have clinical relevance in the prediction of treatment outcome. However, although there were subtle differences in the cephalometric changes and the movement of soft tissue structures between responders and non-responders, these were not statistically significant.

The study cohort was typical of a population of patients with OSA seen in a sleep disorders clinic, with a broad range of

Table 4 Airway parameters without mandibular advancement splint (MAS) and with MAS according to treatment outcome

\begin{tabular}{|c|c|c|c|c|c|c|}
\hline & \multicolumn{3}{|c|}{ Responders $(n=47)$} & \multicolumn{3}{|c|}{ Non-responders $(n=22)$} \\
\hline & Without MAS & With MAS & p Value* & Without MAS & With MAS & p Value* \\
\hline Total airway volume $\left(\mathrm{cm}^{3}\right)$ & $16.1 \pm 0.8$ & $18.1 \pm 1.0$ & $<0.001$ & $17.5 \pm 1.2$ & $18.1 \pm 1.3$ & 0.48 \\
\hline Minimum cross-sectional area $\left(\mathrm{cm}^{2}\right)$ & $0.46 \pm 0.03$ & $0.56 \pm 0.04$ & 0.007 & $0.56 \pm 0.09$ & $0.58 \pm 0.06$ & 0.78 \\
\hline Airway length $(\mathrm{cm})$ & $9.3 \pm 0.1$ & $9.2 \pm 0.2$ & 0.37 & $9.4 \pm 0.2$ & $9.3 \pm 0.2$ & 0.053 \\
\hline \multicolumn{7}{|l|}{ Velopharynx } \\
\hline Volume $\left(\mathrm{cm}^{3}\right)$ & $5.4 \pm 0.4$ & $6.4 \pm 0.4$ & $<0.001$ & $6.2 \pm 0.6$ & $6.7 \pm 0.6$ & 0.27 \\
\hline Antero-posterior dimensions (cm) & $1.11 \pm 0.04$ & $1.15 \pm 0.05$ & 0.19 & $1.18 \pm 0.07$ & $1.19 \pm 0.06$ & 0.78 \\
\hline Lateral dimensions $(\mathrm{cm})$ & $1.62 \pm 0.08$ & $1.92 \pm 0.09$ & $<0.001$ & $1.77 \pm 0.16$ & $1.90 \pm 0.13$ & 0.30 \\
\hline \multicolumn{7}{|l|}{ Oropharynx } \\
\hline Volume $\left(\mathrm{cm}^{3}\right)$ & $3.6 \pm 0.3$ & $4.0 \pm 0.3$ & 0.12 & $3.9 \pm 0.4$ & $3.8 \pm 0.4$ & 0.95 \\
\hline Antero-posterior dimensions (cm) & $1.20 \pm 0.05$ & $1.28 \pm 0.06$ & 0.062 & $1.26 \pm 0.08$ & $1.25 \pm 0.06$ & 0.88 \\
\hline Lateral dimensions $(\mathrm{cm})$ & $2.16 \pm 0.10$ & $2.30 \pm 0.10$ & 0.027 & $2.38 \pm 0.15$ & $2.42 \pm 0.15$ & 0.81 \\
\hline \multicolumn{7}{|l|}{ Hypopharynx } \\
\hline Volume $\left(\mathrm{cm}^{3}\right)$ & $7.0 \pm 0.4$ & $7.7 \pm 0.4$ & 0.003 & $7.4 \pm 0.7$ & $7.6 \pm 0.6$ & 0.68 \\
\hline Antero-posterior dimensions $(\mathrm{cm})$ & $1.37 \pm 0.06$ & $1.49 \pm 0.06$ & 0.021 & $1.37 \pm 0.09$ & $1.43 \pm 0.06$ & 0.50 \\
\hline Lateral dimensions $(\mathrm{cm})$ & $2.51 \pm 0.10$ & $2.58 \pm 0.09$ & 0.19 & $2.49 \pm 0.15$ & $2.38 \pm 0.14$ & 0.36 \\
\hline
\end{tabular}

Data are shown as means \pm SD.

*Without MAS compared with with MAS. 
Figure 6 Representative axial images from a responder and non-responder. In the responder, mandibular advancement can be seen to increase the calibre of the upper airway. This effect does not occur in the nonresponder.
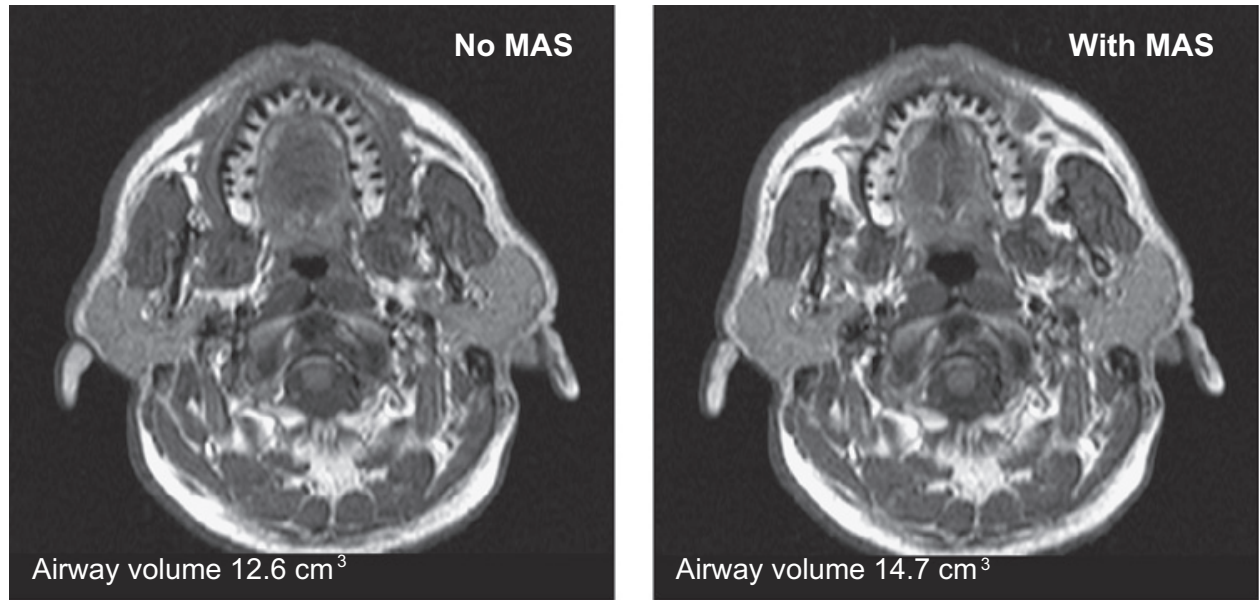

MAS RESPONDER
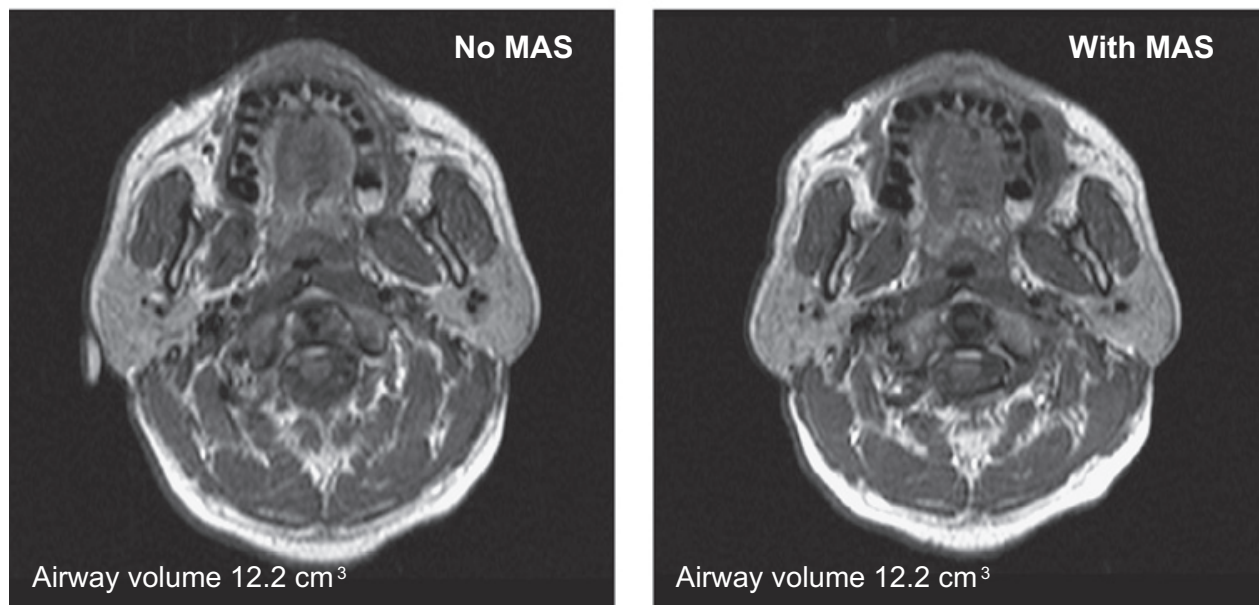

MAS NON-RESPONDER

anthropomorphic characteristics and OSA severity, and thus the results of this study are likely to have good generalisability. However, there are several limitations of this study. By design,

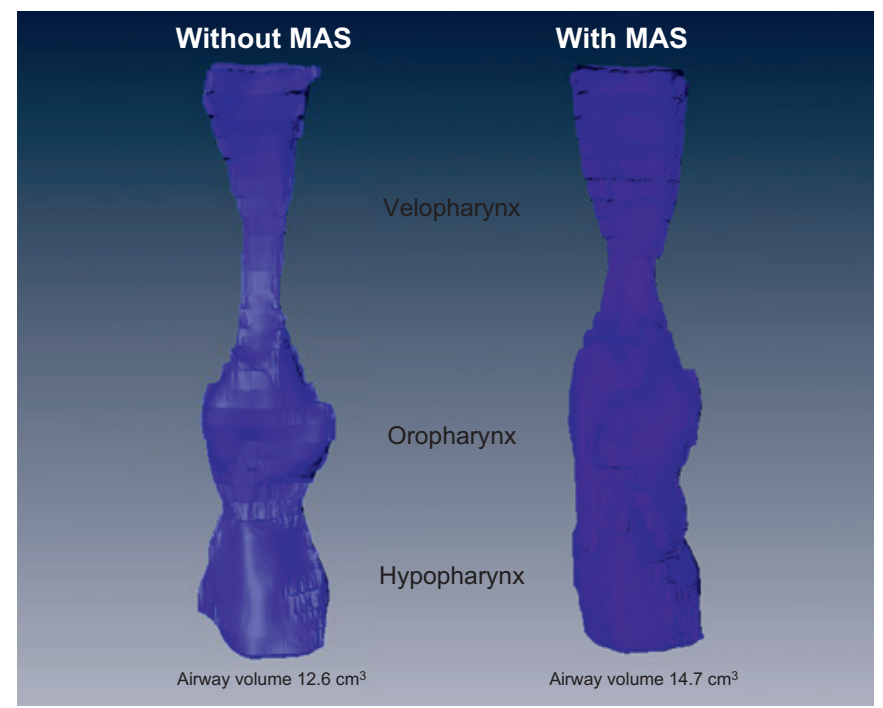

Figure 7 Volumetric reconstructions of the upper airway in a responder (same patient as the responder in figure 6), showing the increase in calibre of the upper airway with mandibular advancement. this imaging study focused on structural parameters, and did not take into consideration the potential additional role of upper airway functional properties (such as neuromuscular factors and airway collapsibility). Furthermore, although we applied an innovative method to examine the movement of soft tissue structures using their centroids, this is an oversimplification of the changes in soft tissue anatomy, including changes in the morphology of individual structures. Other methods of evaluating these subtle changes (eg, finite element analyses) may be necessary to quantify the differences. The study was also performed during wakefulness, and thus the effects of mandibular advancement observed in this study may not be identical to the changes that occur during sleep. Nevertheless, upper airway imaging during wakefulness has strong relevance to defining the structural changes associated with mandibular advancement and the need to develop methods for predicting treatment response that can be implemented into clinical practice. Because the spin-echo MRI scans occurred over several minutes, resulting in averaging of data over many respiratory cycles, we were unable to assess dynamic changes in the airway with and without the MAS. Other imaging modalities, such as anatomical optical coherence tomography, may be better for this purpose. Finally, the custom-made MAS used in this study was of a single device design, which may limit the extent to which the results can be generalised to other devices as different device designs could produce different effects on upper airway 
structure. The study of the effect of different oral appliances on the upper airway may have implications for the choice of an oral appliance for individual patients. Thus, future studies should assess the effect of oral appliance design on a range of biomechanical properties of the upper airway.

In conclusion, this study suggests that the mechanism of action of mandibular advancement is to increase the calibre of the upper airway, predominantly as a result of an increase in the volume of the velopharynx, and is mediated by an increase in its lateral dimensions. The effect of mandibular advancement on the calibre of the upper airway appears to differ between responders and non-responders, with the increase in upper airway calibre with mandibular advancement occurring only in responders. These findings provide novel and fundamental insights into the mechanism of action of MAS, and lay the foundation for future studies aimed at further defining the mechanism of action of MAS, and the factors determining treatment outcome.

Acknowledgements The authors are grateful to Dr Jin Qian, Dr Andrew Ng, Dr Belinda Liu, Dr Keith Wong and the sleep laboratory staff for their assistance.

Funding National Health and Medical Research Council of Australia. SomnoMed provided the oral appliances for this study.

Competing interests PAC contributed to the development of the oral appliance used in this study, which is being commercialised by SomnoMed. He previously served as a consultant and medical advisory board member (2004-2006), and has a pecuniary interest in the company. His department currently receives equipment (oral appliances) and financial support from SomnoMed for investigator-initiated research studies. PAC is a chief investigator in a CPAP clinical trial funded by ResMed, and his department receives equipment support (CPAP machines) for an investigator-initiated study.

Ethics approval This study was conducted with the approval of the University of New South Wales and South Eastern Sydney Area Health Service (Southern Section).

Provenance and peer review Not commissioned; externally peer reviewed.

\section{REFERENCES}

1. Lim J, Lasserson TJ, Fleetham J, et al. Oral appliances for obstructive sleep apnoea. Cochrane Database Syst Rev 2006;(1):CD004435.

2. Kushida CA, Morgenthaler TI, Littner MR, et al. Practice parameters for the treatment of snoring and obstructive sleep apnea with oral appliances: an update for 2005. Sleep 2006:29:240-3.

3. Ferguson KA, Cartwright $R$, Rogers $R$, et al. Oral appliances for snoring and obstructive sleep apnea: a review. Sleep 2006;29:244-62.

4. Cistulli PA, Gotsopoulos H, Marklund M, et al. Treatment of snoring and obstructive sleep apnea with mandibular repositioning appliances. Sleep Med Rev 2004:8:443-57.

5. Hoekema A, Stegenga B, De Bont LG. Efficacy and co-morbidity of oral appliances in the treatment of obstructive sleep apnea-hypopnea: a systematic review. Crit Rev Oral Biol Med 2004:15:137-55.

6. McArdle N, Devereux G, Heidarnejad $\mathrm{H}$, et al. Long-term use of CPAP therapy for sleep apnea/hypopnea syndrome. Am J Respir Crit Care Med 1999;159:1108-14.

7. Weaver TE, Kribbs NB, Pack Al, et al. Night-to-night variability in CPAP use over the first three months of treatment. Sleep 1997;20:278-83.

8. Kribbs NB, Pack Al, Kline LR, et al. Objective measurement of patterns of nasal CPAP use by patients with obstructive sleep apnea. Am Rev Respir Dis 1993; 147:887-95

9. $\mathbf{N g} \mathbf{A T}$, Gotsopoulos H, Qian J, et al. Effect of oral appliance therapy on upper airway collapsibility in obstructive sleep apnea. Am J Respir Crit Care Med 2003; 168:238-41.
10. Johal A, Gill G, Ferman A, et al. The effect of mandibular advancement appliances on awake upper airway and masticatory muscle activity in patients with obstructive sleep apnoea. Clin Physiol Funct Imaging 2007;27:47-53.

11. Kyung SH, Park YC, Pae EK. Obstructive sleep apnea patients with the oral appliance experience pharyngeal size and shape changes in three dimensions. Angle Orthod 2005:75:15-22.

12. Zhao X, Liu Y, Gao Y. Three-dimensional upper-airway changes associated with various amounts of mandibular advancement in awake apnea patients. Am J Orthod Dentofacial Orthop 2008:133:661-8.

13. Sam K, Lam B, Ooi CG, et al. Effect of a non-adjustable oral appliance on upper airway morphology in obstructive sleep apnoea. Respir Med 2006; 100:897-902

14. Ryan CF, Love LL, Peat D, et al. Mandibular advancement oral appliance therapy for obstructive sleep apnoea: effect on awake calibre of the velopharynx. Thorax 1999:54:972-7.

15. Tsuiki S, Lowe AA, Almeida FR, et al. Effects of mandibular advancement on airway curvature and obstructive sleep apnoea severity. Eur Respir $J$ 2004:23:263-8.

16. Tsuiki S, Lowe AA, Almeida FR, et al. Effects of an anteriorly titrated mandibular position on awake airway and obstructive sleep apnea severity. Am J Orthod Dentofacial Orthop 2004;125:548-55

17. Ahmed MM, Schwab RJ. Upper airway imaging in obstructive sleep apnea. Curr Opin Pulm Med 2006;12:397-401.

18. Zeng B, Ng AT, Liu B, et al. Effect of mandibular advancement splint (MAS) on upper airway anatomy [abstract]. Proc Am Thorac Soc 2006;3:A868.

19. Chan AS, Schwab RJ, Zeng B, et al. Mandibular advancement splints and upper airway anatomy in obstructive sleep apnea [abstract]. Am J Respir Crit Care Med 2008:177:A939

20. Mehta A, Qian J, Petocz P, et al. A randomized, controlled study of a mandibular advancement splint for obstructive sleep apnea. Am J Respir Crit Care Med 2001; 163:1457-61.

21. Zeng B, Ng AT, Darendeliler MA, et al. Use of flow-volume curves to predict oral appliance treatment outcome in obstructive sleep apnea. Am J Respir Crit Care Med 2007:175:726-30.

22. Zeng B, $\mathrm{Ng} \mathrm{AT}$, Qian J, et al. Influence of nasal resistance on oral appliance treatment outcome in obstructive sleep apnea. Sleep 2008;31:543-7.

23. Gotsopoulos H, Chen C, Qian J, et al. Oral appliance therapy improves symptoms in obstructive sleep apnea: a randomized, controlled trial. Am J Respir Crit Care Med 2002:166:743-8.

24. Gotsopoulos H, Kelly JJ, Cistulli PA. Oral appliance therapy reduces blood pressure in obstructive sleep apnea: a randomized, controlled trial. Sleep 2004;27:934-41.

25. Pitsis AJ, Darendeliler MA, Gotsopoulos $\mathrm{H}$, et al. Effect of vertical dimension on efficacy of oral appliance therapy in obstructive sleep apnea. Am J Respir Crit Care Med 2002:166:860-4.

26. American Sleep Disorders Association. EEG arousals: scoring rules and examples: a preliminary report from the Sleep Disorders Atlas Task Force of the American Sleep Disorders Association. Sleep 1992;15:173-84.

27. Rechtschaffen A, Kales A. A manual of standardized terminology, techniques and scoring system for sleep stages of human subjects. Los Angeles, CA: Brain Information Service/Brain Research Institute, University of California, 1968.

28. Schwab RJ, Pasirstein M, Kaplan L, et al. Family aggregation of upper airway soft tissue structures in normal subjects and patients with sleep apnea. Am J Respir Crit Care Med 2006:173:453-63.

29. Schwab RJ, Pasirstein M, Pierson R, et al. Identification of upper airway anatomic risk factors for obstructive sleep apnea with volumetric magnetic resonance imaging Am J Respir Crit Care Med 2003;168:522-30.

30. Welch KC, Foster GD, Ritter CT, et al. A novel volumetric magnetic resonance imaging paradigm to study upper airway anatomy. Sleep 2002;25:532-42.

31. Cooke MS, Wei SH. An improved method for the assessment of the sagittal skeletal pattern and its correlation to previous methods. Eur J Orthod 1988;10:122-7.

32. Isono S, Tanaka A, Tagaito Y, et al. Pharyngeal patency in response to advancement of the mandible in obese anesthetized persons. Anesthesiology 1997;87:1055-62.

33. Ryan CF, Lowe AA, Li D, et al. Magnetic resonance imaging of the upper airway in obstructive sleep apnea before and after chronic nasal continuous positive airway pressure therapy. Am Rev Respir Dis 1991;144:939-44.

34. Schwab RJ, Pack Al, Gupta KB, et al. Upper airway and soft tissue structural changes induced by CPAP in normal subjects. Am J Respir Crit Care Med 1996;154:1106-16. 